\title{
Fala sério, Thalita: é a literatura de massa uma estratégia eficiente para a formação do leitor literário?
}

\section{RESUMO}

Jaime dos Reis Sant'Anna isantann@ hotmail.com Universidade Estadual de Londrina Londrina, Brasil.
O objetivo desse trabalho é discutir se a literatura de massa (LM), em especial os bestsellers seriados como os seis títulos de Fala sério!, de Thalita Rebouças, é uma estratégia eficiente para a formação de leitores literários no Ensino Básico. A preocupação se justifica devido ao uso crescente da LM por professores de língua materna, sobretudo quando apoiados por estudos acadêmicos com os quais buscam legitimar suas práticas docentes. Depois de fundamentar a discussão acerca do conceito de literatura de massa (Eco; Adorno; Benjamin) e sua relação com a formação de leitores literários (PCN; OCEM; DCE-PR), a abordagem do tema é proponente: os professores de LP precisam conhecer a LM, mas não devem tomá-la como ponte para formar leitores na sala de aula; os professores devem pensar a LM como ponte para conhecer a mundividência de seus alunos, a fim de estreitar o diálogo e estabelecer a mediação necessários à formação de leitores literários críticos.

PALAVRAS-CHAVE: Formação de leitor. Literatura de massa. Thalita Rebouças. 


\section{INTRODUÇÃO}

A proposta inicial deste artigo é por demais ampla, confesso, para não ter que reconhecer - e para que, antes de mim, não o façam outros - que é um tanto pretensiosa. Discutir o ensino de literatura e a formação de leitores literários no Ensino Básico; avaliar a utilização da chamada literatura trivial ou de massa, como uma das ferramentas com que se tem trabalhado a formação de leitores, na sala de aula; refletir acerca do papel mediador do professor de Língua Portuguesa no processo de formação do leitor literário; criticar a atitude docente, pretensamente democrática e libertária, quando da opção pela literatura de massa, como forma de atender às supostas escolhas livres de estudantes adolescentes; apontar os elementos ideológicos que agem na busca de legitimação das práticas de leituras literárias contemporâneas; e, finalmente, ajudar o professor de língua materna na construção de uma postura propositiva perante o fenômeno. Tudo isso aplicado à realidade brasileira no que tange à produção literária de massa, sobretudo ao representante nacional do fenômeno da cultura de massa de best-sellers seriados, como é o caso dos seis títulos da série Fala sério! de Thalita Rebouças, cuja expressiva vendagem configura amplo sucesso para os padrões editoriais brasileiros.

Sei que os limites impostos pela natureza ensaística desse artigo não permitirão que eu dê conta integralmente dos assuntos envolvidos. Por isso mesmo, talvez fosse melhor ouvir a voz da razão, recuar na empreitada, desmembrar o assunto em vários artigos, eliminando o risco de superficialidade intelectual. Ou botar a "mão na massa" e correr os riscos.

Não que seja incompossível a abordagem de todos esses temas em um único texto, pois ideologia, literatura juvenil de massas, mercado editorial, escolhas anárquicas, práticas de leitura literária e ensino de Literatura dialogam entre si. Esses são assuntos que ocupam as preocupações presentes nas propostas de formação de leitores literários, notadamente representadas por documentos oficiais norteadores do ensino de língua materna, tais como os Parâmetros Curriculares Nacionais (PCN), as Orientações Curriculares do Ensino Médio (OCEM) e as diversas diretrizes curriculares estaduais para o ensino de Língua Portuguesa. E eu - que venho lidando com essa gama de assuntos em minhas pesquisas no âmbito da Universidade Estadual de Londrina-PR e em cursos de formação continuada ministrados para os experientes professores de Língua Portuguesa da rede estadual de ensino -, prefiro evocar tudo para uma boa prosa acadêmica sobre formação de leitores literários.

Mas, fala sério, ninguém lê a "obra completa" de Thalita Rebouças impunemente. E eu (de novo), tantas vezes sério na produção acadêmica, me pego receoso do contágio dessa casta de literatura, e me pergunto, com medo de minha própria introspeç̧ão, sobre a medida com que esse tipo de literatura contamina seus leitores. Afinal, "um pouco de fermento leveda toda a massa". E me questiono, ainda, a respeito das razões que levam ao levedo uma massa nada desprezível de pesquisadores, a ponto de defenderem, em congressos de leitura e em revistas especializadas, a viabilidade de começar um trabalho eficiente de formação de leitores nas escolas, a partir da adoção de leituras de best-sellers seriados, como Harry Potter, de Johanne K. Rowling, Crepúsculo, de Stephenie 
Meyer, Percy Jackson, de Rick Riordan ou Diário de um banana, de Jeff Kinney, dentre outros campeões de venda.

Em 2012, no 3o Congresso Internacional de Leitura e Literatura Infantil e Juvenil, sediado na PUC/RS, me surpreendi com a ingenuidade com que um neófito congressista expunha seu entusiasmo para com as vantagens da utilização das obras de Johanne K. Rowling nas aulas regulares de Língua Portuguesa e como tal experiência deveria servir como paradigma para a formação de leitores literários nas escolas públicas de uma cidade do sertão brasileiro; mas a estupefação foi irrelevante comparável ao desconforto perante o silêncio acrítico dos subjugados ouvidos dos demais congressistas.

A questão que subjaz à discussão não é a inegável antipatia crassa nos meios acadêmicos para com a literatura de massa; nem tão pouco o curto tempo entre o sucesso editorial destas obras e o trabalho do crítico literário, notadamente daqueles inseridos no âmbito das pesquisas universitárias, das práticas de ensino de Língua Portuguesa, sobretudo no que diz respeito à formação de leitores literários. Com efeito, o problema começa pelo desconhecimento dessa chamada literatura trivial no meio acadêmico. Lembro-me, aliás, da perplexidade com que li pela primeira vez a afirmação peremptória de um renomado crítico literário, cujo nome prefiro não declinar - pois são tantos -, a respeito da obra de um consagrado autor de literatura de massa: "Paulo Coelho? Nunca li e não gostei". Depois, quando percebi que tal atitude, comum no meio acadêmico, também era contumaz nos cadernos dominicais de cultura dos grandes jornais, fui me habituando a este tipo de manifestação.

É evidente, portanto, que existe um relativo despeito e defraudação em relação à literatura que engorda os bolsos dos agentes envolvidos no processo editorial e do qual a academia não participa; é provável, mesmo, que exista algum receio intelectual e resistência à exposição em face à "novidade" - do ponto de vista meramente cronológico, vale registrar - que tais obras apresentam. Enquanto isso ocorre, os professores de língua materna no Ensino Básico e demais agentes mediadores de leitura literária se perguntam a respeito do papel das literaturas de massa, sobretudo os best-sellers seriados, e da sua eficácia ou não no processo de formação de leitores - nos moldes do leitor crítico, como preceituam os PCN, as OCEM.

\section{ENTRE BEST-SELLERS E FOLHETINS, O COMPLAC(I)ENTE PROFESSOR E O PA(Z)CIENTE LEITOR}

No entanto, para além das posturas descomprometidas com o rigor acadêmico, compreendo que o fenômeno contemporâneo da literatura de massa, ou dos best-sellers seriados de grande sucesso, sobretudo daqueles voltados para o público juvenil que compõe o corpo discente com o qual lidamos nas escolas, não é um fenômeno restrito aos tempos atuais. Na verdade, elas refletem a transferência do mecenato do artista sustentado pelos nobres, até o fim do século XVIII, para uma nova realidade vivenciada pela sociedade durante a Revolução Industrial, respaldada por critérios comerciais que atendam às demandas do público consumidor.

Algo semelhante ocorreu no século XIX, por ocasião da literatura publicada nos jornais, os chamados folhetins. Muito já se tem escrito sobre a relação entre 
o folhetim e a literatura de massa. Para os objetivos deste artigo, basta lembrar que, popularizados na França, os folhetins receberam edição em livro de obras originalmente publicadas em jornal, como é o caso de Captain Paul, de Alexandre Dumas, de 1838. Segundo Moisés a partir daí, "proliferaram as infindáveis novelas de folhetins, estampadas nos jornais e depois reunidas em volume" e que o "acolhimento por parte do público fazia que os editores lançassem as novelas em livro" (MOISÉS, 1997, p. 108).

No Brasil, são ilustrativos os casos de literatura publicada em folhetins como $O$ guarani, de José de Alencar, e Memórias de um sargento de milícias, de Manuel Antônio de Almeida, dentre tantos outros -, e que depois foi lançada em livro. O texto de Almeida é, na verdade, paradigmático: publicado em folhetins dominicais do Jornal do Comércio, entre junho de 1852 e julho de 1853, como bem apontou Jarouche, a narrativa obedeceu à repercussão de cada capítulo junto ao público, estruturando-se ao sabor da repercussão e interação com os leitores e ampliando-se de acordo com os interesses dos donos do jornal, que viam no folhetim um impulso para a subscrição de novas assinaturas (JAROUCHE, 2000 , p. 39). Com o tempo, vieram a publicação das Memórias de um sargento de milícias em livro impresso, a consolidação da fortuna crítica, o reconhecimento de seu espaço no cânone literário brasileiro e, como consequência consensual, sua utilização pelos professores de Língua Portuguesa no ensino de Literatura e na formação de leitores literários.

Segundo apontou Bosi em artigo intitulado "Os estudos literários na Era dos Extremos", a literatura de massa do século XIX e a literatura de massa das últimas décadas distinguem-se, sobretudo, pela tendência para o exagero que a contemporaneidade demonstra em relação ao tratamento de duas marcas de sua essencialidade. De um lado, a explosão de uma literatura de efeitos imediatos, "especular e espetacular", em que o leitor e o autor perseguem a representação do show da vida, incrementado e amplificado; do outro lado, aquilo a que Bosi designou como hiperintertextualidade calcada nas convenções de escrita e conteúdo, uma hipermediação marcada pela profusão incontida de pastiches, paródias e aglutinações de subdiscursos (BOSI, 2002, p. 248-256).

A questão que se coloca em relação à literatura de massa atual, assim como aconteceu com aqueles folhetins que resistiram ao tempo, extrapola o matiz estético, pois algumas características comuns à literatura de massa contemporânea podem ser igualmente verificáveis na literatura de massa representada pelos folhetins do século XIX. Em ambos os casos, demonstram a capacidade de reprodução e distribuição de bens culturais, a que Walter Benjamin chamou de "bens de consumo que a indústria cultural vê como produtos que devem ser explorados segundo seus fins comerciais" (BENJAMIN, 1980, p.8).

A possibilidade cada vez maior de edições com tiragens elevadas, proporcionadas pelo desenvolvimento da indústria gráfica e das publicações em formato digital, tornou o livro, inclusive o de ficção, uma mercadoria acessível ao grande público, consolidando a indústria cultural. Benjamin aponta que "multiplicando as cópias, elas transformam o evento produzido apenas uma vez num fenômeno de massas" (BENJAMIN, 1980, p. 8). O fenômeno é bom, pois franqueia o acesso à cultura àqueles que até então não dispunham de condições para se aproximar de um livro, devido aos parcos recursos; no entanto, 
intensifica o controle das forças do capital sobre a produção artística e as ações alienadoras da indústria cultural.

A facilitação do acesso aos "bens de consumo cultural" também não diz respeito apenas ao aspecto financeiro, tornando o produto cultural uma mercadoria finalmente alcançável pelo poder aquisitivo das massas. Para além dos baixos custos possibilitados pela produção em série, a facilitação se dá no campo da recepção das obras. Autores e editores esforçam-se para desobstruir os elementos literários responsáveis por quaisquer dificuldades de assimilação do público.

Nesse sentido, podemos entender que tanto os folhetins do século XIX quanto a literatura de massa dos últimos 50 anos buscam o que, para Benjamin é o principal papel desempenhado pelas massas para os interesses do mercado e a dupla tendência que as caracterizam: "de um lado, que as coisas se lhe tornem, tanto humana como espacialmente, mais próximas"; e de outro lado, e como consequência da primeira, uma tendência quase que inevitável para que tais procedimentos venham a "depreciar a qualidade artística da obra" (BENJAMIN, 1980, p. 9). Em outros termos, tais produções tendem a expor o leitor ao mínimo de estranhamentos que Ihe dificultem a leitura, fornecendo-Ihe competência tão somente para o ato de leitura desse tipo de literatura.

Um olhar atento que coteje obras representativas destes dois momentos - o dos folhetins e o das literaturas de massa - revela características literárias que se assemelham. O estudo de Flávio Kothe sobre a literatura trivial (1994), revela que, em ambos os casos, encontramos determinadas recorrências: os capítulos são curtos e/ou pelo menos simétricos, produzidos para atender ao interesse editorial, seja dos jornais, seja das editoras; as narrativas são lineares, para facilitar a compreensão do leitor apoucado; os enredos episódicos são valorizados, para garantir as expectativas dos leitores ávidos por entretenimento; a linguagem é simplificada, para favorecer um contingente maior de leitores habituados aos diálogos comezinhos; a construção do herói clássico é calcada no modelo burguês, com o qual o grande público facilmente se identifica; os valores éticos são maniqueístas, predominando a distinção clara entre o bem e o mal, o certo e o errado, o justo e o desonesto, a fim de se tornarem facilmente identificáveis; a superioridade da nobreza de caráter, nos termos dos moldes burgueses de referência, é preferível em detrimento aos caracteres usuais; e, por fim, o final feliz, responsável por dar sentido à vida por meio da obra literária junto ao público médio.

Caso tomemos os best-sellers seriados contemporâneos, como os mencionados Harry Potter, Crepúsculo e Percy Jackson, resguardadas algumas situações peculiares, não precisaremos de muito esforço para observar nessas obras as características acima apontadas.

No Brasil das duas últimas décadas, quando alguns milhões de brasileiros foram inseridos no mercado consumidor, o livro tornou-se mais um dos produtos a que se lhes permitiu o acesso, alavancando a produção. Para comprovar, evoco dados extraídos de duas fontes distintas, de modo intencional, pois enquanto uma reflete o fenômeno no âmbito escolar, a outra lida com a leitura literária para além dos muros da escola. De um lado, as informações obtidas nas três pesquisas dos "Retratos da Leitura no Brasil", edições de 2000, 2007 e 2011, realizadas e coordenadas pelo Instituto Pró Livro, permitem comparar o 
significativo crescimento do mercado editorial, e sobretudo, dos livros de ficção voltados para o público juvenil. Do outro lado, as informações oficiais do Programa Nacional Biblioteca da Escola (PNBE) possibilitam verificar o avanço alcançado nos últimos anos, quando as ações governamentais fizeram com que, de 2003 a 2012, chegassem às 140 mil escolas cadastradas no Ministério da Educação, algo em torno de 65 milhões de livros, notadamente de obras literárias. Diante desse quadro de ampliação do acesso ao livro, não se deve estranhar que a literatura de massa enquanto parcela substancial da lucrativa indústria cultural queira estender sua participação na distribuição do produto livro de literatura, quer no âmbito escolar por meio dos acervos do PNBE, quer no mercado editorial fora do âmbito escolar.

Nesse contexto mercadológico do livro de literatura juvenil, é necessário considerar que se nos depara um fenômeno capitalista, em que a literatura é um produto vendável e o leitor é um consumidor a ser conquistado. De tal maneira, que se evidencia neste quadro a figura do escritor de best-sellers - produto literário de sucesso, pressuposto - como um trabalhador atrelado aos mecanismos alienadores do capital, conforme bem acentuou Eagleton (s.d.), em Marxismo e crítica literária, citando Karl Marx: "um escritor [...] é um trabalhador não na medida em que produz ideias, mas na medida em que enriquece a editora, que trabalha por um salário" (EAGLETON, s.d., p.108). Nessa obra, o autor inglês discute a perspectiva do escritor que produz a obra de arte (literatura) de acordo com os interesses de seu patrão (editora), em um cenário em que o escritor/operário está inserido no contexto do mercado editorial, e cuja produção visa primeiro e essencialmente ao ganho monetário: "os livros não são apenas estruturas de significado - são também mercadorias produzidas pelas editoras e vendidas no mercado com lucro" (EAGLETON, s.d., p.107).

Por isso, a preocupação do pesquisador que busca a construção de um instrumental teórico para o aprimoramento do trabalho do professor de língua materna redobra quando ele se depara com a maneira acrítica como a literatura de massa tem sido apontada por outros tantos pesquisadores como ferramenta para a formação de leitores literários no Ensino Básico. Cada vez mais, ouço as vozes emanadas de congressos acadêmicos que discutem a formação do leitor literário - engrossadas pelas comunicações veiculadas em seus anais e que ganham a publicidade do ciberespaço -, olvidando-se da natureza mercadológica que permeia esse tipo de literatura. Trata-se da perspectiva daqueles que têm se posicionado a favor da opção pelas leituras de obras da literatura de massa como ferramenta para a formação de leitores nos currículos do Ensino Básico. Alguns argumentos para fundamentar essa atitude têm se repetido à exaustão, quase todos mais ou menos marcados por um discurso que Antoine Compagnon (2001) e Luiz Percival Leme Brito (2003), dentre outros, algures têm chamado de "mitos da leitura".

Um desses argumentos afirma tratar-se de uma estratégia (no sentido militar que a palavra sugere) que considera sábio apropriar-se do gosto médio difundido pelo mercado editorial entre os adolescentes para formar leitores literários: tática mais ou menos parecida com o "se não pode com eles, junte-se a eles".

Em um cenário de "guerra do livro", esquecem-se os incautos que estamos lidando com as forças ideológicas do poderoso mercado editorial, cujas armas se alastram por meio das mais diversas plataformas midiáticas, e que a validação acadêmica para este tipo de literatura configura-se em mais uma instância 
legitimadora do sistema. Enquadra-se, em termos da avaliação de Theodor Adorno e Max Horkheimer nos moldes de uma "indústria cultural capaz de adaptar seus produtos ao consumo das massas e, ao mesmo tempo, determinar a necessidade do próprio consumo", conferindo-lhe o recorrente "encanto da novidade" (ADORNO; HORKHEIMER, 2010 [1947], p. 19).

Outro argumento, comum aos defensores da adoção estratégica da literatura de massa como ferramenta para a formação de leitores nos projetos escolares, distorce a perspectiva de Roland Barthes acerca da "fruição", tomando o conceito como se fora tão somente a capacidade de um texto determinar no leitor o supremo prazer de ler, uma espécie de leitura hedonista. Vale lembrar que, para Barthes, enquanto o texto de prazer é aquele "que contenta, enche; que vem da cultura, não rompe com ela e está ligado a uma prática confortável de leitura", o texto de fruição é aquele que coloca o leitor "em estado de perda, que desconforta e faz entrar em crise sua relação com a linguagem" (BARTHES, 1987, p. 20).

Não é o caso, aqui, de assumir a atitude descabida de desprezar o valor do prazer da leitura no processo de formação de leitores na fase adolescente da vida. Todavia, mais que o prazer, deve-se buscar compreender a teleologia implícita na construção de leitores críticos, como tão bem Marisa Lajolo definiu um leitor "para quem cada nova leitura desloca e altera o significado de tudo o que ele já leu, tornando mais profunda sua compreensão dos livros, das gentes e da vida" (LAJOLO, 2002, p. 52). O que se obsta, portanto, é a hipervalorização do prazer per si em detrimento da expansão dos horizontes possibilitados pela leitura, ainda que nascidos de algum desconforto.

No que tange à literatura trivial ou de massa, aplica-se a constatação formulada por Osakabe \& Frederico, e citada nas OCEM (2004, pp. 62-63), para cujos autores, esse tipo de literatura reflete algumas tendências predominantes na atualidade e que se confirmam nas práticas escolares de leitura da literatura. Para eles, a "substituição da literatura difícil por uma literatura considerada mais digerível" reduz o valor da literatura no processo formativo dos alunos, produzindo como grave consequência os "deslocamentos ou fuga do contato direto do leitor com o texto literário".

Dessa forma, as críticas à literatura de massa e seus desdobramentos, quer na constituição de um mercado consumidor que se expande junto à emergente nova classe média brasileira, não se estabelecem como uma antipatia contumaz da academia diante da literatura que alcança um grande público. Caso contrário, estaríamos jogando junto com a "água suja da banheira" deste tipo de literatura, títulos que no passado foram produzidos como literatura de massa e hoje são tomados como textos canônicos, de "alta literatura"; estaríamos repetindo com a abordagem da literatura de massa contemporânea, a mesma iconoclastia reacionária exercida pelos educadores, até os anos 1970, contra os malefícios das Histórias em Quadrinhos, deixando de compreender - como atualmente compreendemos - seu papel na formação do público adolescente de nosso tempo.

\section{PAUSA PARA O ENTRETENIMENTO E TEMPO PARA A PROPOSTA}


Nesse momento das reflexões, penso ser necessário evocar uma pausa para reafirmar que estamos lidando com uma indústria cultural que reduz literatura a um produto de divertimento, entretenimento, consumo. E reafirmar que, longe de tripudiar sobre toda a literatura de massa, pretendemos desafiar os professores de Língua Portuguesa para que conheçam a literatura de massa a que seus alunos estão submetidos fora dos muros escolares, a fim de construir pontes que viabilizem uma docência proponente, rumo à execução do projeto de formação de leitores que extrapole o puro ato de ler para alcançar a leitura crítica, transformadora.

Umberto Eco refere-se à produção literária em geral, dividindo-a em dois tipos peculiares: a "literatura de entretenimento" e a "literatura de proposta". Segundo ele - para quem as expressões "literatura de massa", "baixa literatura" e "paraliteratura" são inadequadas, tanto quanto as expressões "alta literatura", "literatura séria", "boa literatura" e "literatura erudita" -, a literatura de entretenimento e a literatura de proposta deveriam ser compreendidas a partir de dois critérios que as distinguissem, a saber, a originalidade e o esforço.

Para Eco, os critérios originalidade e esforço balizam as Literaturas de Entretenimento e as Literaturas de Proposta. Não precisamos de muito "esforço" para depreender que aquela carece de originalidade, enquanto esta é plena de originalidade; que a primeira busca se enquadrar no gosto médio, a fim de alcançar um público mais amplo; enquanto a segunda, afastando-se do sensocomum, visa à inovação, quer seja por meio dos elementos da narrativa (personagens, enredo, cronotópos, temas), quer seja devido à linguagem mais elaborada. Dessa forma, enquanto a Literatura de Entretenimento exige pouco esforço do leitor, cuja experiência é largamente considerada para facilitar a assimilação por meio da vinculação texto-leitor, a Literatura de Proposta aponta para permanentes desafios de expressividade e de recursos linguísticos (ECO, 1989, p.104). Entendo, em face dessa distinção, que a formação do tipo de leitor literário que pretendemos somente ocorrerá a partir da utilização da literatura que o apresentar à originalidade, à inovação, à linguagem, etc., submetendo-o ao desconforto do trabalho que isso, nos termos apontados por Eco, acarreta.

Em suma, a perspectiva de Eco vê na Literatura de Entretenimento a aproximação dos modelos televisivos ou "neo-hollywooddianos" - como demonstrarei ser o caso da série Fala sério!, de Thalita Rebouças -, produzindo decalques extraídos destas plataformas; ao passo que a Literatura de Proposta, como bem sugere sua designação, cria o desconforto no leitor, ao lhe propor o contato com elementos narrativos inovadores, com aquilo que o desafia à linguagem elaborada e com o alargamento da mundividência

\section{FALA SÉRIO, VOCÊ ACHA MESMO UMA ESTRATÉGIA EXEQUÍVEL O SALTO DA LITERATURA DE MASSA PARA A LITERATURA DE PROPOSTA?}

Não raras vezes, encontro artigos acadêmicos que defendem a revisão da postura da escola perante a literatura de entretenimento ou de massa, argumentando que esse matiz literário poderia fomentar o gosto pela leitura entre os brasileiros pouco habituados para, em seguida ou concomitantemente, 
Para legitimar tal posicionamento, chega-se a invocar como suporte crítico, o texto de José Paulo Paes (1987) - precocemente convertido em Teoria do Degrau - intitulado "Faz falta uma literatura brasileira de massa", no qual o poeta, tradutor e ensaísta revela sua angústia quanto ao que chama de "falta de leitores literários no Brasil". Nele, Paes lamenta não existir uma literatura de massa brasileira, "uma literatura média de entretenimento, estimuladora do gosto e do hábito da leitura", a partir da qual se alcançaria "o patamar mais alto" da literatura de proposta, da literatura canônica.

Grosso modo, e levada a hipótese ao extremo, procurei um exemplo recente de literatura de entretenimento produzida no Brasil e que poderia servir de degrau para a literatura mais elaborada. Optei - sem pretensões de elaborar um estudo de caso, claro está - por testar a hipótese aplicando-a a série Fala sério!, de Thalita Rebouças., cujos seis títulos alcançaram a marca de mais de 1,2 milhão de exemplares vendidos, multiplicando-se por outros tantos milhões de leitores e com forte repercussão no ciberespaço. A bem-sucedida recepção dos livros de Rebouças confirma a sugestão de Umberto Eco para explicar o alcance da literatura trivial ou de massa: "um livro obtém sucesso somente em dois casos: se dá ao público o que ele espera ou se cria um público que decide esperar o que o livro Ihe dá" (ECO, 1989, p. 104).

A série escrita por Rebouças - até o momento em que concluo este artigo - é composta de seis títulos, a saber, Fala sério, mãe! (2004); Fala sério, professor! (2006); Fala sério, amor! (2007); Fala sério, amiga! (2008); Fala sério, filha! (2011); Fala sério, pai! (2013). E quando este artigo for publicado ou quando você o estiver lendo, tanto pode ser que novos títulos da série tenham vindo a público, quanto também pode ser que a fórmula editorial tenha se exaurido e quase ninguém mais se lembre - fala sério! - quem foi Thalita Rebouças.

Linguagem simples, acessível; protagonista adolescente; temas pertinentes no percurso formativo do indivíduo; projeto gráfico agradável: marcas da literatura infantojuvenil contemporânea, apontadas por Colomer (2003, p. 5053), que em maior ou menor grau, estão presentes na coleção de Rebouças. Some-se a esses ingredientes da literatura infantojuvenil o atrelamento a um sistema multimidiático retroalimentador em torno da produção e da divulgação dessas obras, tais como resenhas das obras em jornais de grande circulação e em blogues formadores de opinião; presença ostensiva da autora em feiras e mostras literárias; participação em quadros regulares de programas de televisão; palestras em escolas e clubes de leitura; debates em livrarias especializadas; entrevistas em talk shows; e, sobretudo, uma paraliteratura refletida em adaptações para outras linguagens comunicacionais, como teatro e cinema, tirinhas e histórias em quadrinhos: receita de sucesso de vendas de Fala sério! e de obras similares.

A série produzida por Rebouças se encaixa no modelo de Literatura de Entretenimento apontado por Eco, com destaque para algumas marcas identitárias. Trata-se de literatura caracterizada pelo constante decalque de modelos extraídos da zona de conforto de uma produção amplamente difundida por matizes como a televisão ou o cinema. Aliás, a pergunta contumaz nas redes sociais e artigos veiculados no ciberespaço - uma curiosidade que move fãs e críticos da obra de Thalita Rebouças - diz respeito a se a protagonista Malu, da série Fala sério!, apresentada ao público pela escritora carioca a partir do primeiro livro da coleção, intitulado Fala sério, mãe!, de 2004, é decalcada 
(alguns ousariam referir-se a plágio) da personagem televisiva Tati, criada pela humorista Heloísa Perissé. De fato, a adolescente Tati, popularizada pelo bordão "fala sério", foi construída com os mesmos moldes caricaturais que também estão presentes na personagem Malu. Todavia, a personagem Tati estreou três anos desta, como uma das alunas do programa "Escolinha do Professor Raimundo", transmitido pela Rede Globo desde a temporada 2001, mesmo ano em que ela foi inserida na comédia teatral "Cócegas". Em 2003, a personagem de Perissé aparece em livro intitulado $O$ diário de Tati, posteriormente ampliada para o cinema, em 2012, com filme de título homônimo.

A leitura dos cinco títulos que seguem a publicação de Fala sério, mãe! não constitui nenhum desafio ou esforço para os leitores. A razão principal é a escassez de recursos literários, restringindo-se às repetições das fórmulas consagradas na narrativa do primeiro volume, sobretudo no que se refere à estereotipização da protagonista, da linguagem coloquial da adolescente carioca de classe média, em torno da variação dos mesmos temas, cuja manutenção nos volumes seguintes é estratégica para a "fidelização" de leitores consumidores.

A linguagem dos seis volumes da série também prima pela recorrência de anacronismos, os quais denotam certo desleixo para com a construção da narrativa. Exemplo disso são as constantes referências às tecnologias comunicacionais inexistentes ou de acesso restrito no tempo diegético da narrativa, e que se reflete em perda de verossimilhança. Publicado em 2004, Fala sério, mãe! registra, na primeira parte, as memórias da mãe e na segunda parte as impressões da protagonista até ela completar 21 anos; abrange, portanto, o período entre 1983 e 2004. Na obra, há uma profusão de referências à internete, aos blogues juvenis e a aparelhos de CDs em carros populares, mencionados em episódios que ocorreram há 15 ou 20 anos na vida da protagonista ou de sua mãe, ou seja, em épocas bem distantes da popularização desta tecnologia. Ou seja, o texto faz referência ao acesso rápido à internete, em episódios ocorridos em 1994 (Rebouças, 2004, p. 66), ou 1996 (Rebouças, 2004, p. 78); faz referência a blogues pessoais em episódio ocorrido em 1995 (Rebouças, 2004, p. 67); e faz referência até mesmo ao uso de $C D$ player no carro de modelo popular da mãe da protagonista, em episódio que relata seu período de gestação, que se supõe ter ocorrido em 1982 (REBOUÇAS, 2004, p. 25).

Para aquém de servir de trampolim ou de "degrau" na escalada rumo à literatura canônica ou de proposta, o mais previsível é que a literatura de entretenimento consagrada pelo senso comum forme um leitor hábil apenas na leitura deste tipo de leitura, cuja falta de saciedade clama ao mercado editorial mais do mesmo. Até aí, estamos apenas diante de uma Literatura de Entretenimento que preenche um nicho mercadológico carente de publicações, que é o do consumidor adolescente, natural e tradicionalmente atrelado às propostas escolares.

Para os objetivos dessas reflexões, vale lembrar a avaliação de Adorno \& Horkheimer, para os quais o ideal de divertimento propalado pela indústria cultural responsável por essa literatura de massa "transforma-se numa mentira patente [que] produz uma lengalenga [...] que as pessoas toleram nos best-sellers [...] como um ingrediente ao mesmo tempo penoso e agradável" e que tem como objetivo, ainda segundo os pensadores alemães, "dominar com maior segurança na vida real seus próprios impulsos humanos" (ADORNO; HORKHEIMER, 2010 [1947], pp. 12-13). 
Em suma, nos seis títulos da série Fala sério!, Thalita Rebouças produz literatura que atende aos conflitos oriundos do mundo adolescente, diverte com suas obras destinadas a seu público consumidor, atentando tão somente para as demandas da indústria cultural. Os mecanismos multimidiáticos retroalimentam o desejo do leitor e Rebouças proporciona o que o público deseja, garantia de sucesso.

No bojo de um sistema de coisas em que o mercado costuma ditar práticas e gostos, gerando o consumo de produtos até então desnecessárias, a fim de auferir lucros, nada de surpreendente constatar que a publicação de livros pelas editoras esteja descomprometida com o propósito de formação de leitores críticos. Como já afirmamos anteriormente, citando Eagleton (s.d.) - e que com tal frequência é esquecida, que precisamos repetir -trata-se de uma relação mercadológica em que a editora é o patrão, o escritor é o trabalhador e a literatura é uma mercadoria.

O que causa estranhamento é a complacente ingenuidade de educadores que veem neste tipo de produção cultural o aludido degrau para a formação de leitores críticos, uma postura que vai de encontro às propostas dos principais documentos oficiais norteadores do ensino de Língua Portuguesa no Ensino Básico. Para os Parâmetros Curriculares Nacionais: Língua Portuguesa (PCN), o objetivo é "a formação de leitores capazes de reconhecer as sutilezas, as particularidades, os sentidos, a extensão e a profundidade das construções literárias" (1998, p. 27). Para as Diretrizes Curriculares da Educação Básica: Língua Portuguesa (DCE), do Paraná, estado em que atuo na formação inicial e continuada dos professores de Língua Portuguesa, a formação de leitores literários críticos se concretiza quando o alunado se torna apto para o "reconhecimento das vozes sociais e das ideologias presentes no discurso", quando tem autonomia intelectual para "a construção de sentido de um texto literário e na compreensão das relações de poder a ele inerentes" (2008, p. 57).

A série Fala sério!, bem como a maioria dos títulos da literatura de massa ou de entretenimento, produzida no Brasil ou fora dele, que ela representa, não atende aos objetivos traçados pelos documentos oficiais no que diz respeito à formação de leitores literários críticos. Os professores de Língua Portuguesa devem saber de sua existência e conhecer seu conteúdo, a fim de estabelecer pontes para estreitar o diálogo com nossos alunos adolescentes; mas não fazer deles a ponte que aproxima o adolescente do professor envolvido na formação de leitores literários.

\section{CONCLUSÃO}

Nesse contexto mercadológico do livro de literatura juvenil, é necessário considerar que, por um lado, se nos depara um fenômeno capitalista, em que a literatura foca na diversão para tornar-se um produto vendável e o leitor é visto como um consumidor a ser conquistado e fidelizado.

Por outro lado, deve-se considerar que a expansão do número de livros de literatura vendidos/comprados, como vimos, não se transfere automaticamente para a conquista de leitores literários. Nem tão pouco se presta para a formação 
de leitores literários críticos, nem habilita para o exercício da percepção de vozes ideológicas e das intencionalidades sub-reptícias que se escamoteiam nesse tipo de discurso.

A literatura de massa - e seus maiores representantes contemporâneos, os best-sellers seriados - não são os instrumentos adequados para alcançarmos esses objetivos propostos pelos PCN, OCEM e DCE-PR. De tal maneira, que se evidencia neste quadro a figura do escritor de best-sellers (produto de sucesso, portanto) como um trabalhador atrelado aos mecanismos alienadores do capital.

Diante deste quadro, a primeira grande constatação é aquela que enxerga na proposta de uso da literatura de massa para a formação do leitor crítico, como se fora um degrau para se chegar às almejadas "altas literaturas", uma estratégia ineficiente e que reflete uma atitude de crassa ingenuidade intelectual; complacente, mas não consciente.

Trata-se de postura que, sem garantir a eficácia metodológica para alcançar o objetivo maior, que é construção do leitor maduro, os poucos resultados que porventura venha obter se convertem em distorção da realidade, cujo maior risco é servir de instrumento ideológico de legitimação tão desejado pelo mercado editorial.

As propostas apontadas pelas OCEM e refletidas em DCE para o ensino de Língua Portuguesa visam ao alargamento do horizonte de expectativas do alunado, para o amadurecimento da visão de mundo, para a construção do espírito crítico, formando um leitor que perceba as diversas vozes presentes em um texto literário. $O$ principal propósito deste artigo foi manter viva a discussão sobre se a literatura de massa, sobretudo os chamados best-sellers seriados, como Harry Potter (J. Rowling) ou Fala sério! (T. Rebouças), se configura como estratégia metodológica capaz de formar leitores literários no Ensino Básico.

A preocupação que moveu a reflexão foi a percepção do crescente uso dessas literaturas por professores de Língua Portuguesa, cada vez mais apoiados por estudos acadêmicos que se disseminam no ciberespaço, e com os quais eles legitimam suas complacentes práticas docentes. Por isso, busquei ajudá-los, propondo a seguinte atitude: os professores de língua materna precisam conhecer a literatura de massa - e, o quanto possível, os produtos da indústria cultural que assediam os adolescentes -, mas não devem trabalhar com obras da literatura de massa como leitura que objetive tornar-se ponte ou degrau para formar leitores nas lides da sala de aula; os professores de língua materna devem pensar a literatura de massa - e, o quanto possível, os produtos da indústria cultural -, conhecendo os elementos constituintes de sua natureza, como uma ponte que permita construir um diálogo estreito entre professores e seus alunos, com vistas à formação de leitores literários críticos. 


\title{
Fala sério, Thalita: is the mass literature an effective strategy to formation of literary readers?
}

\begin{abstract}
The aim of this paper is to discuss if reading mass literature - as the Fala sério! series by Thalita Rebouças - is a good strategy to form literary readers in Basic Education. The preoccupation concerns the use of mass literature by Portuguese teachers, a practice that is supported by some academic studies. So, after discussing the concepts of mass literature (Eco; Benjamin; Adorno) and its relation to a formation of readers (as recommended by official Brazilian documents, such as PCN, OCEM and DCE), I hope to assist teachers with a proposal: they need to know about mass literature, but they mustn't accept it as a bridge to form readers. The teachers must think mass literature as a bridge to build a dialogue between teachers and students.
\end{abstract}

KEYWORDS: Mass literature. Literary readers. Thalita Rebouças. 


\section{REFERÊNCIAS}

ADORNO, Theodor W; HORKHEIMER, Max. "A Indústria Cultural: O Esclarecimento Como Mistificação das Massas" In: Dialética do Esclarecimento: fragmentos filosóficos. [1947]. Tradução de Guido Antônio de Almeida. 2010. Disponivel em https://direitoufma2010.files.wordpress.com/2010/05/aindustria cultural.pdf. Acessado em: 12 de agosto de 2016.

BARTHES, Roland. o prazer do texto. Trad. Jacó Guinsburg. São Paulo: Perspectiva, 1987.

BENJAMIN, Walter. A obra de arte na época de suas técnicas de reprodução. Trad. José Lino Grünnewald... [et al.]. Coleção Os pensadores [BENJAMIN, Horkheimer, Adorno, Habermas]. São Paulo: Abril Cultural, 1980.

BOSI, Alfredo. Literatura e resistência. São Paulo: Cia das Letras, 2002.

BRASIL/SEMTEC. Parâmetros Curriculares Nacionais: Língua Portuguesa. Brasília: Mec/Secretaria de Ensino Fundamental. 1998.

BRASIL/SEMTEC. PCN+ ensino médio: orientações educacionais complementares aos Parâmetros Curriculares Nacionais. Volume Linguagens, códigos e suas tecnologias. Brasília: MEC/SEMTEC, 2002.

BRASIL/SEMTEC. Orientações curriculares do ensino médio. Brasília: MEC/Semtec, 2004.

BRITTO, Luiz Percival Leme. Leitura e participação. Contra o consenso: cultura escrita, educação e participação. Campinas-SP: Mercado das Letras, 2003.

COMPAGNON, Antoine. O demônio da teoria: literatura e senso comum. Trad. Cleonice Paes Barreto Mourão, Consuelo Fortes Santiago. Belo Horizonte: Ed. UFMG, 2001.

COLOMER, Teresa. A formação do leitor literário: narrativa infantil e juvenil atual. Trad. Laura Sandroni. São Paulo: Global, 2003.

EAGLETON, Terry. Ideologia: uma introdução. Trad. Silvana Vieira, Luis Carlos 1997. 
Marxismo e crítica literária. Trad. António Sousa Ribeiro. Porto: Edições Afrontamento, s/d.

ECO, Umberto. Sobre os espelhos e outros ensaios. Trad. Beatriz Borges, Rio de Janeiro: Nova Fronteira, 1989.

Apocalípticos e integrados. Trad. Pérola de Carvalho. Série Debates 19. São Paulo: Perspectiva, 2000. Disponível em: file:///C:/Users/user/Downloads/Apocali301pticos\%20e\%20Integrados $\% 20$ -\%20em\%20portugues\%20-Umberto\%20Eco.pdf. Acessado em: 02 fevereiro 2017.

Instituto Pró-Livro. Retratos da Leitura no Brasil - Relatório 2011. Brasília. II Seminário Nacional, 28 de março de 2012. O relatório da pesquisa "Retratos da Leitura no Brasil" - edição 2008. Disponível em: http://www.prolivro.org.br. Acessado em 18.09.2016.

Retratos da Leitura no Brasil - Relatório 2007. (Organizador Galeno Amorim). São Paulo: Imprensa Oficial: Instituto Pró-Livro, 2008. Disponível em http://www.imprensaoficial.com.br/retratosdaleitura/rl1.pdf. Acessado em 20.09.2016.

Retratos da Leitura no Brasil - Relatório 2000

http://www.snel.org.br/wp-

content/uploads/2012/09/pesquisa 2001 mercado comprador.pdf. Acessado em 20.09.2018.

JAMOUCHE, Mamede Mustafá. "Galhofa sem melancolia: as Memórias num mundo de luzias e saquaremas". In: ALMEIDA, Manoel Antônio de. Memórias de um Sargento de Milícias. São Paulo: Ateliê, 2000.

o folhetim e a crônica. Disponível em http://www.eca.usp.br/cje/anexos/depaula/aula4_folhetim.pdf. Acessado em 15.10.2015.

KOTHE, Flávio. A narrativa trivial. Brasília: Editora da Universidade de Brasília, 1994

LAJOLO, M. Do mundo da leitura para a leitura do mundo. São Paulo: Ática, 2002. 
MOISÉS, Massaud. A criação literária. Prosa I. Fôrmas em prosa, conto, novela, romance. 16ạ edição, revista e atualizada. São Paulo: Cultrix, 1997.

PAES, José Paulo, "Faz falta uma literatura brasileira de massa". In: Jornal Folha de São Paulo, 10.01.1989, Caderno E, p. 8.

PARANÁ. Secretaria de Estado da Educação. Departamento da Educação Básica. Diretrizes Curriculares de Educação Básica: Língua Portuguesa. Curitiba: Imprensa Oficial, 2008.

PERRISÉ, Heloísa. O diário de Tati. Rio de Janeiro: Objetiva, 2003.

REBOUÇAS, Thalita. Fala sério, mãe! [2004]. 2a edição, Rio de Janeiro: Rocco, 2012.

Recebido: 22 fev. 2017

Aprovado: 02 mai. 2017

DOI: $10.3895 /$ rl.v19n24.5588

Como citar: SANT'ANNA, Jaime dos Reis. Fala sério, Thalita: é a literature de massa uma estratégia eficiente para a formação do leitor literário?. R. Letras, Curitiba, v. 19, n. 24, p. 43-58, mar. 2017. Disponíve em: <https://periodicos.utfpr.edu.br/rl>. Acesso em: XXX

Direito autoral: Este artigo está licenciado sob os termos da Licença Creative Commons-Atribuição 4.0 Internacional. 